Boise State University

ScholarWorks

Counselor Education Faculty Publications and

Presentations

Department of Counselor Education

$7-1-2010$

\title{
Family Functioning and the Development of Trust and Intimacy Among Adolescents in Residential Treatment
}

\author{
Kenneth M. Coll \\ Boise State University \\ Stephanie Powell \\ Fielding Graduate University \\ Patti Thobro \\ Cathedral Home for Children \\ Robin Haas \\ Cathedral Home for Children
}




\title{
Family Functioning and the Development of Trust and Intimacy Among Adolescents in Residential Treatment
}

\author{
Kenneth M. Coll \\ Boise State University
}

\author{
Stephanie Powell \\ Fielding Graduate University
}

\author{
Patti Thobro \\ Robin Haas \\ Cathedral Home for Children
}

\begin{abstract}
This study examined relations between family cohesion and adaptability (as measured by the Family Adaptability and Cohesion Scales-III) and the formation of trust and intimacy (assessed with the Measure of Psychosocial Development) among adolescents in residential treatment. Bivariate correlation revealed a significant association between family cohesion and adaptability and psychosocial stages of trust and intimacy. Regression analyses revealed that family cohesion predicted trust, and that trust is significantly influential in the formation of intimacy. Discussion and treatment implications are included.
\end{abstract}

Keywords: family functioning, Family Adaptability and Cohesion Scales-III, adolescent residential treatment, trust, intimacy

Adolescence is considered by many to be the most challenging and critical period of human development. As a stepping stone to young adulthood, the period of adolescence brings significant changes in physical, cognitive, social, and emotional development (Buist, Dekovic, Meeus, \& van Aken, 2004; Laible, Carlo, \& Raffaelli, 2000). Of particular interest to the current study are the social and emotional aspects of trust and intimacy in adolescent development. While most individuals are able to navigate adolescent stages of development without significant distress, others are not as fortunate. The transition appears to be more complicated for adolescents who experience a sense of mistrust and feel disconnected with their family (Daniels, 1990).

Developmental researchers generally agree that the quality of relationships in an individual's life play an important role in psychosocial development (Richmond \& Stocker; 2006; Zegers, Schuengel, van IJzendoorn, \& Janssens, 2008). Furthermore, relationships marked by conflict are shown to have a negative impact on adolescents' wellbeing (Dekovic, 1999). While many studies have focused on the role of parental influences and adolescent development, relatively few studies have examined the specific characteristics of familial interactions that many be linked to developmental difficulties with trust and intimacy.

\section{Adolescent Development, Trust and Intimacy}

Erickson's psychosocial theory of development focused on the formation of the self through relational interactions in social and cultural environments (Erickson, 1963). Erickson proposed that individuals experience eight developmental stages in the course of the life span. Each stage is marked by its own unique challenge(s), resulting from biological, psychological, and cultural influences (Hawley, 1988).

While Erickson noted identity formation as the primary developmental task during adolescence, Sullivan (1952) proposed intimacy as closely linked to identity development, and suggested that the level of felt security in familial relationships guides the desire and capacity for increased intimacy in future interactions. Sullivan indicated that intimacy is linked to the formation of identity and serves as an important developmental task in adolescents.

Mikulincer (1998) suggested that "a sense of trust is a necessary condition for the development of secure, intimate, and satisfactory relationships" (p. 1211), and there is evidence to suggest that adolescents who have difficulty developing and maintaining close interpersonal relationships are guided by negative trust-related experiences from the past (Hill, Fonagy, Safier, \& Sargentet, 2003; McWhirter et al., 2004). Siegel (1999) indicated that mistrust 
diminishes the capacity for affect-regulation and interferes with one's ability to derive satisfaction from interpersonal relationships. Such disruptions in psychosocial development can lead to maladaptive behaviors as misguided attempts to regulate emotions.

Rempel, Holmes, and Zanna (1985) noted that trust involves three essential features: (a) felt security in the reliability and predictability of a relational other, (b) the belief than significant others are concerned with one's own needs and can provide comfort in times of stress, and (c) feelings of confidence in the quality of interpersonal relationships.

Ornduff (2000) explains that basic relationship paradigms develop in the early months of life and provide a foundation for which individuals organize subsequent interpersonal experiences. A child's representational world is an accumulation of emotional experiences with caregivers which become internalized and guide expectations and behavior in future relationships. If a child's representational world is shaped by uncertainty, fear, or negative trustrelated experiences, he or she will develop insufficient interpersonal understanding and is likely to react to people with fear, mistrust, or uncertainty (Ornduff, 2000; Wallin, 2007). Hofer (2006) concludes that when caregivers are either absent or inadequate, physiological and behavioral changes occur within the child; resulting in altered, “...complex, changing patterns of vulnerability over the lifespan” (p. 87). +

\section{Family as a Dynamic System}

Adolescents are participating members of a larger dynamic family system, and emotional experiences are dependent on the reciprocal influence of familial interactions (Gunderson \& Lyons-Ruth, 2008; Miller, 2008). In other words, a child's representational world at the individual level is also comprised of shared representations at the family level. Over time, emotions and behavior of any one family member are the result of “.... a three-way interaction between his or her own emotional processes, those of the persons he or she is interacting with, and the emotional character of the interaction itself (Miller, 2008, p. 17). These interactions function as implicit "rules" to maintain the preservation and equilibrium of family bonds (Hill et al., 2003). Wallin (2007) explains, "[The rules] are rigorously implemented because their violation challenges states of mind and ways of being that have made emotional survival possible” (p. 36).

There is substantial evidence that family dynamics have a pervasive influence on psychosocial behaviors from one generation to the next, even if a member of a new generation has not had contact with the previous one (Fenell \& Weinhold, 1989; Fonagy \& Target, 2005; Fraley, 2002; Horne \& Ohlsen,1982). This phenomenon can be understood through various theoretical views. From an attachment perspective, parenting behaviors are guided by internal representations from past experiences with one's own caregivers (Boger, Tompson, Briggs-Gowen, Pavlis, \& Carter, 2008; Gunderson \& Lyons-Ruth, 2008; Trumpeter, Watson, O’Leary, \& Weathington, 2008); while cognitive behavioral theory explains parenting through "schemas" which channel beliefs about what children need (Azar, Nix, \& Makin-Byrd, 2005; Sameroff \& MacKenzie, 2003). Internal representations and schemas have the power to influence parental behavior in ways that can be sensitive and nurturing, or potentially maladaptive when dominated by negative emotion (Siegel, 1999).

\section{Cohesion vs. Conflict}

Healthy family functioning is exhibited by parent-child communication that is open and relaxed, particularly about experiences of positive and negative emotions (Kerns, Tomich, Aspelmeier, \& Contreras, 2000). From the view of the representational family, cohesion and flexibility are conceptualized not only in terms of physical proximity, but also in terms of family members' capacities to emotionally respond to each other in ways that are contextually accurate and developmentally meaningful. In other words, healthy families share a "state of mind" that enable them to maintain a balance between "...intimacy and sharing on the one hand, and individuality on the other" (Hill et al., 2003, p. 211). In the context of the current study, the construct of intimacy is not romantic selection. Rather, it is the capacity for closeness and reciprocal feelings of empathy within the family system.

Richmond and Stocker (2006) suggest that adolescents from families that are emotionally connected, warm, and flexible demonstrate healthy psychological adjustment. 
Buist et al. (2004) agree that secure family bonds enable adolescents to acknowledge distress, engage in constructive problem-solving behavior, seek support from others, and regulate affect through felt security in early relationships.

By contrast, adolescents whose early relationships were characterized by negative trust-related experiences (i.e., neglect, trauma, intrusiveness, inconsistency, and inaccurate communication) demonstrate difficulty in coping with distress and relationship conflict (Mikulincer, 1998; Richmond \& Stocker, 2006). Moreover, some large scale studies have discovered that relational learning in adolescence is highly influenced by the level of family engagement and perceived emotional availability of family members (Coll, Juhnke, Thobro, Haas, \& Robinson, 2008; Trumpeter et al., 2008). It should be noted that adolescents' perceptions of parental empathy, rather than overt parental behaviors or intentions, were found to have the greatest impact on the development of trust and intimacy (Trumper et al., 2008).

Long term consequences of family conflict have been documented by Colman et al. (2009). Their longitudinal study revealed that adolescents whose families were marked with conflict, were more likely to develop severe externalizing behaviors (i.e., delinquency and aggression) compared to adolescents from cohesive families. They were also more likely to drop out of school and face adversity across multiple domains of functioning including mental health, interpersonal relationships, family functioning, and socioeconomic status. Additionally, Colman et al. noted that without appropriate intervention, psychosocial deficits, such as mistrust in relationships, were likely to continue into adulthood.

It has been suggested that family conflict, while not a direct causal agent of psychopathology, creates disruptions in the formation of affect regulation and generates vulnerability for the development of psychopathology and risk behavior (Chen \& Simons-Morton, 2009; Miklowitz \& Chang, 2008; Siegel, 1999). Indeed, poor family relations have been linked to a number of adolescent psychosocial issues including anxiety disorders (Keeley \& Storch, 2009), depression and suicide (Allen, Porter, McFarland, McElhancey, \& Marsh, 200; Steinberg \& Davila, 2008; Taliaferro, Rienzo, Miller, Pigg, \& Dodd, 2008), bipolar disorder (Miklowitz \& Chang, 2008), conduct disorder (Chen \& Simons-Morton, 2009; Coll et al., 2008; Colman et al., 2009; Jensen, 2008; Laible et al., 2000; Zegers et al., 2008), self injurious behavior (Crowell et al., 2008; Herr, Hammen, \& Brennan, 2008), and substance use disorders (Chassin \& Handley, 2006; Coll, Thobro, \& Haas, 2004; Fromme, 2006; Tucker, Ellickson, \& Klein, 2008; Schindler et al., 2005; van der Vorst, Engels, Meeus, Dekovic, \& Vermulst, 2006).

Adolescents who demonstrate psychopathology and high risk behavior not only suffer the effects of family conflict, but are often referred for inpatient or residential care. A study by Tonge, Hughes, Pullen, Beuafoy, and Gold (2008) revealed that adolescent inpatients were challenged by multiplicity of issues ranging from comorbid psychiatric disorders to chronically-impaired interpersonal functioning. Moreover, adolescents referred for residential treatment have often been exposed to multiple risks or chronic stress, and tend to carry the negative influences of their previous environment with them into treatment (Green et al., 2001; Zegers et al., 2008). Considering that adolescents often return to their families upon discharge, is important to examine possible underlying psychosocial factors (e.g., trust and intimacy) related to family functioning in effort to coordinate treatment at the individual and family level.

The purpose of this study was twofold. First, we aimed to examine specific constructs of psychosocial development associated with perceived family functioning among adolescents in residential treatment. We hypothesized that family cohesion and adaptability would significantly predict the level of trust and intimacy in interpersonal relationships. Second, we aimed to provide treatment recommendations to facilitate the development of felt trust and intimacy among adolescents and their families within a residential treatment setting.

\section{Method}

\section{Participants}

Data for the present study were collected from adolescents residing six months or longer at a residential treatment center in the Rocky Mountain Region of the United States. The agency is a nationally recognized residential treatment facility/therapeutic community that offer specialized educational, psychological, and therapeutic services for adolescents. All participants were referred to this facility for one or more of the following reasons: (a) noncompliance in school, (b) history of criminal activity, or (c) having been a referral to Child Protective Services. 
The participants $(\mathrm{N}=328)$ ranged in age from $12-17$, with a mean age of 14.9. Sixty-three percent were male $(\mathrm{n}=$ 207) and 37\% were female $(n=121)$. Ninety percent $(n=296)$ identified their ethnicity as European American, with $5 \%(n=16)$ Hispanic, and the remaining 5\% $(n=16)$ American Indian/Alaska Native. The average length of stay was between 6 and 10 months $(\mathrm{M}=8.6$ months).

\section{Procedure}

Assessment instruments were administered by Master's-level, licensed counselors or social workers. Assessments were standardized and administered within the first three weeks of participants' admittance to the facility per requirement from the agency's accrediting body - the Joint Commission for the Accreditation of Health Care (JCAHO). Facilities accredited by JCAHO adhere to multiple standards of professional patient care.

\section{Instruments}

Measure of Psychosocial Development (MPD). The MPD was used to assess levels of psychosocial development related to trust and intimacy in interpersonal relationships. The MPD is a self-report instrument based on Eriksonian constructs of adolescent and adult personality development (Hawley, 1988). The MPD provides an index of psychosocial health based on Erikson's criteria. The MPD consists of 112 self-descriptive statements which measure positive and negative developmental attitudes

Normative data consisted of a sample of 2,450 individuals, ages 13-86. Approximately 620 of the 2,450 norm group were adolescents (ages 13 to 17). Hawley (1998) indicates that the adolescent norm group was considered a nondelinquent sample. Both reliability and validity for the MPD are robust. Test-retest reliability exceeded .80 on a sample 108 adolescents and adults. Internal consistency has been calculated on a sample of 372 adolescents and adults with coefficients ranging from .64 to .84. As Hawley (1988) noted, "the scales have acceptable levels of internal consistency, particularly since coefficient alpha provides a conservative estimate of reliability. These data provide support for the conceptual base underlying the item selection procedure for the MPD” (p. 15).

Comparison analysis of the MPD with other self-report measures of Erikson's theory demonstrated support for construct validity (including convergent and discriminant validity) of the MPD in assessing psychosocial development. Extensive multitrait and multimethod analyses with normative data (as required by Campbell \& Fiske, 1959) methodology proved strong support for discriminant validity. The correlations of measures of different constructs were smaller than correlations of measure of the same construct at a rate of $97.3 \%$. Hawley (1988) notes that the MPD identifies resolution scores that "provide a representation of the status conflict resolution for each of the eight stages. A low resolution (for example R1) suggests developmental stress resulting from lack of adequate resolution of that specific stage (for example, for Stage 1, Trust versus Mistrust” (p. 7). Two resolution scales were used in this study; Trust versus Mistrust and Intimacy versus Isolation. High Trust versus Mistrust resolution is defined as being open and receptive to new people, experiences, and ideas. Conversely, low resolution in this area is defined as viewing the world as unsafe, threatening, and a cold place (Hawley, 1988). High Intimacy versus Isolation resolution is defined as seeking emotionally close relationships in which to share thoughts and feelings, confiding in friends and being easily available to others. Low resolution in this area is defined as not being able, or refusing to share anything close to self with anybody (Hawley, 1988).

Family Adaptability and Cohesion Evaluation Scales-III (FACES-III). The FACES-III was used to measure the level of family functioning (Maynard \& Olson, 1987). The FACES-III is a self report questionnaire that consists of 20 items (with Likert-type scale ranging from 1 to 4) developed for use with adolescents as young as 12 years of age. The FACES-III has demonstrated strong test-retest reliability (.83) and discriminate validity between dysfunctional families and control groups (Olsen et al., 1985).

The FACES-III consists of two scales: The Adaptability Scale and The Cohesion Scale. The Adaptability Scale consists of 10 even-numbered items that measure flexibility in family functioning. It ranges from four levels of extremely low, rigid (scores of 10-19) to more moderate levels, structured (20-24) and flexible (25-29) to extremely high, chaotic (30-50). Examples of questions include: "Different persons act as leaders in our family" and "Parent(s) and children discuss punishment together". As Olsen et al., document "family adaptability (change) has to do with the extent to which the family system is flexible and able to change. Family adaptability is defined as: the ability of 
the family system to change its power structure, role relationships, and relationship rules in response to situational and developmental stress" (p.3).

The Cohesion Scale consists of 10 odd-numbered items and The Cohesion Scale score is determined through engagement (i.e., the level of family connectedness and emotional bonding). The Cohesion Scale ranges from extremely low disengaged (10-31) to more moderate levels separated (32-37) and connected (38-43) to extremely high, enmeshed (44-50). Examples of questions include: "Family members like to spend free time with each other" and "Family members ask each other for help". Internal consistency estimates for the Cohesion Scale based on a national sample of 3,700 participants (ages 12-19) is .77 (Maynard \& Olson, 1987). Olsen et al., identify that "family cohesion assesses the degree to which family members are separated from or connected to their family. Family cohesion is defined as: the emotional bonding that family members have toward one another ” (p.3).

\section{Results}

Descriptive statistics and bivariate correlations between variables were calculated for family cohesion, adaptability, trust, and intimacy. Mean scores indicated that adolescents in residential treatment tended to report their family as structured $(M=25.2, S D=8.8)$ and disengaged $(M=29.9, S D=9.4)$, and demonstrated mistrust (per trust $/$ mistrust resolution) $(M=5.9, S D=8.5)$, at the $24^{\text {th }}$ percentile, and isolation (per intimacy/isolation resolution $)(M=5.4, S D$ $=7.9)$, at the $12^{\text {th }}$ percentile. The pattern of connections indicated that family cohesion was significantly associated with adaptability $(\mathrm{p}<.001)$ and trust $(\mathrm{p}<.01)$, and that adaptability was significantly associated with trust $(\mathrm{p}<.01)$ and intimacy $(\mathrm{p}<.001)$.

Stepwise regression was conducted to explore the accuracy of family cohesion and adaptability in predicting the level of trust. Regression coefficients revealed that cohesion contributed to the model, $\mathrm{R}^{2}=.02, \mathrm{R}^{2} \mathrm{adj}=.017, F(1$, 327,)=6.73, \mathrm{p}=.01$.

We then entered cohesion, adaptability, and trust in the model to explore predictors of intimacy. Results indicated an overall model of one predictor (trust) that was significantly associated with intimacy, $\mathrm{R}^{2}=.401, \mathrm{R}^{2} \mathrm{adj}=.399, F(1$, 327, ) $=218.27, \mathrm{p}<.001$. This model accounted for $40.1 \%$ of the variance in the level of intimacy. Summary of results are presented in Table 1.

\section{Insert Table 1 Here}

\section{Discussion}

This study examined whether family functioning predicted psychosocial development of trust and intimacy among adolescents in a residential treatment setting. Our results are consistent with previous studies of adolescents development that have linked maladaptive behaviors with family interactions that manifest low cohesion, enmeshment, and parenting styles that are controlling or emotionally insensitive (Coll et al., 2008; Dekovic, 1999; Lee \& Bell, 2003; Murray et al., 2006; Trumpeter et al., 2008).

As hypothesized, adolescents who reported low levels of family engagement were also more likely to describe their families as rigid or inflexible. It was also discovered that the level of perceived family engagement and flexibility was significantly related to lower levels of psychosocial functioning with regard to trust and intimacy. Disengaged scores represented the highest level of separation (i.e., very low engagement, attachment bonds, and perceived support), indicating that adolescents perceived their families as emotionally distant with negative and confusing communication patterns (e.g., inaccurate displays of anxiety, anger, and conflict) between family members.

Interestingly, cohesion predicted the level of trust, but when added to the model, trust (rather than cohesion) predicted the level of intimacy as measured by the MPD. This particular finding leads to various inferences about the integral role of trust in interpersonal relationships and psychosocial well being. Consistent with previous studies, it appears that adolescents who hold a negative sense of trust lack sufficient ability to develop long-lasting, satisfying relationships. From a clinical perspective, the current results have numerous implications for therapeutic intervention. 


\section{Treatment Recommendations}

Some studies acknowledge the effectiveness of relationship-focused interventions over traditional behavior modification for adolescents in residential treatment (Moses as cited in Hardy, 2007). The most salient features in the current study were the lack of trust and intimacy in interpersonal relationships stemming from an inflexible and disengaged family environment. Therefore, treatment should be aimed at modifying internal representations of mistrust, and focus on increasing sensitivity and accuracy of family interactions (Zegers et al., 2008).

There is some evidence to suggest that modification of internal representations is possible. In Main and Goldwyn's (1994) study, they discovered a subgroup of secure, autonomous individuals who described painful childhood histories normally associated with poor family functioning. Nonetheless, they were able to reflect coherently and speak collaboratively about the past. Main and Goldwyn categorized this group as "earned secure", and proposed that because they were able to stand both inside and outside one's experience, they were able to develop a sense of trust and the capacity for satisfying interpersonal relationships. Furthermore, earned secure adults were able to accurately interpret another's emotions and engage in collaborative, emotional dialogue with their own children; thus successfully interrupting the transgenerational pattern of family dysfunction.

With this in mind, the underlying goal of treatment is to assist adolescents in becoming "earned secure" individuals. We recommend intervention approaches that integrate attachment, cognitive-behavioral, and psychodynamic theories, with an emphasis on three key mechanisms of change: (a) increasing trust through the therapeutic alliance, (b) fostering the capacity for reflective functioning, and (c) improving the accuracy of family dialogue through caregiver involvement.

\section{Trust through the Therapeutic Alliance}

In the beginning stages of treatment, Young, Klusko, and Weishaar (2003) suggest therapists focus on more on empathy than problem solving, and seek to create an environment that fosters safety, security, and acceptance. Therapists will find it useful to establish themselves as a "secure base" wherein adolescents can explore their needs, desires, and emotions (Bowlby, 1988). Young et al. (2003) note that the exploration of one's emotions can be a painful and anxiety-provoking process because it is often in direct contrast with previous experiences where one's needs were misinterpreted, invalidated, or punished.

The therapist's role as a secure base is to be a trusted companion through whom the adolescent can become confident that his or her needs and emotions will be validated and responded to in an affirming manner. This relational process sets the stage for new interactive patterns which can eventually be applied outside the therapeutic setting (Young et al., 2003).

\section{Development of Reflective Functioning}

Reflective functioning is a method of putting emotions (especially unwanted emotions) into words for reflection and review. This process is described by Fonagy (2001) and others as mentalization because it allows individuals to reflect on the reality of their own experiences. Wallin (2007) compares mentalizing to using a telescope. It refines one's vision of distant experiences by bringing them closer for view. Choi-Kain and Gunderson (2008) offer a more comprehensive definition of mentalization as "the way humans make sense of their social world by imagining the mental states (e.g., beliefs, motives, emotions, desires, and needs) that underpin their own and others' behaviors in interpersonal interactions” (p. 1127).

Therapists should foster a sense of security while encouraging adolescents to probe their relational experiences, especially experiences that are emotionally charged. This exercise assists adolescents in developing the capacity to feel one's feelings and simultaneously reflect on their meaning (Fonagy \& Target, 2006). Siegel (1999) explains that reflection allows new information to assimilate, and encourages adolescents to revalue their representational world. When individuals are able to interpret their own mind as well as others, they integrate new forms of affect regulation which enhance the development of trust and intimacy (Fonagy, 2001; Wallin, 2007). 


\section{Improving Accuracy of Family Dialogue through Caregiver Involvement}

The development of trust and intimacy in families dominated by conflict necessitates the involvement of caregivers and influential family members. Hardy (2007) indicated that "caregiver involvement in the treatment process...is believed to be an important contributor to positive treatment outcomes" (p. 33). Cozolino (2006) pointed out that the formation of trust and intimacy is fundamentally rooted in the sharing of emotional states between family members. Therapists should assist families in learning how to negotiate their needs and desires based on respect and reciprocity (Young et al., 2003). In order to attain this goal, two key elements of family dialogue must be considered in treatment: (a) the influence of affectively-charged discourse (including verbal and nonverbal sharing of emotional states), and (b) ruptures in communication and misunderstandings (Hill et al., 2003; Lyons-Ruth, 1999).

Family members must be confident that they share a common "interpretive frame" of experiences. In other words, there must be a level of assurance in the family that "humor is humor and not criticism, and that expressions of sadness are sadness and not anger” (Hill et al., 2003, p. 206). When communication lacks clarity, it creates a type of confusion that makes one's membership in the family more fragile. In turn, responses will likely be misunderstood or illicit an incoherent and distorted response, thus exacerbating the level of mistrust in the family.

Developing a common interpretive frame depends on the confidence of family members in their ability to recognize and repair ruptures in communication or misunderstandings (Lyons-Ruth, 1999). Therapists can assist family members through psychoeducational approaches that focus on what Bateman (as cited in Hill et al., 2003) termed, metacommunication, or "communication about communication" (p. 206). Talking about communication and the ways in which one's state of mind can be misinterpreted by another can often lead to an understanding about misunderstanding between two parties (Choi-Kain \& Gunderson, 2008).

Finally, several studies acknowledge that adolescents benefit from parenting characterized by sensitivity (i.e., warmth \& acceptance), accurate communication, predictability, and the encouragement of psychological autonomy, while maintaining a high level of supervision (Allen et al., 2007; Chassin \& Hadley, 2006; Dekovic, 1999; Laible et al., 2000; Riggs, Sahl, Greenwald, \& Atkison, 2007). Therapists should provide psychoeducation designed to increase these specific, interpersonal parenting skills.

\section{Limitations}

The current study includes some limitations. Because the participants were in a residential setting, there is some question whether our findings can be generalized to populations outside of residential treatment. An additional limitation of the study is that our measurements did not tap into the complexity and multifaceted nature of the construct of trust. Mikulincer (1998) noted that many individuals differ in the meanings they ascribe to a sense of trust, and further research is needed to support the accuracy of our results.

Our findings might not be mutually exclusive, and there is a possibility of confounding factors that play a role in the formation of trust and intimacy. For example, we did not examine early experiences of trauma which may influence disruptions in trust and intimacy formation. Additionally, we did not specifically examine gender differences related to perceived family functioning, but some studies have noted that adolescent females demonstrate heightened emotional awareness in family relationships (Murray et al, 2006; Steinberg \& Davila, 2008; Sunday et al., 2008). Further research is needed to determine the role of gender in the development of trust and intimacy and perceived family functioning.

Given these limitations, our treatment recommendations will require future outcome research to determine overall efficacy. Finally, one must consider the practicality of family intervention, especially for rural treatment facilities. Future studies should explore creative ways to connect families during the treatment process through the use of technology. 


\section{References}

Allen, J. P., Porter, M., McFarland, C., McElhaney, K. B., \& Marsh, P. (2007). The relation of attachment security to adolescents’ paternal and peer relationships, depression, and externalizing behavior. Child Development, 78, 1222-1239.

Azar, S. T., Nix, R. L., \& Makin-Byrd, K. N. (2005). Parenting schemas and the process of change. Journal of Marital and Family Therapy, 31, 45-58.

Boger, K. D., Tompson, M. C., Briggs-Gowan, M. J., Pavlis, L. E., \& Carter, A. S. (2008). Parental expressed emotion toward children: prediction from early family functioning. Journal of Family Psychology, 22, 784-788.

Bowlby, J. (2008). A secure base. London: Routledge.

Buist, K. L., Dekovic, M., Meeus, W. H., \& van Aken, M. (2004). Attachment in adolescence: A social relations model analysis. Journal of Adolescent research, 19, 826-850.

Campbell, D. T., \& Fiske, D. W. (1959). Convergent and discriminant validation by the multitrait-multimethod matrix. Psychological Bulletin, 56, 81-105.

Chassin, L., \& Hadley, E. D. (2006). Parents and families as contexts for the development of substance use and substance use disorders. Psychology of Addictive Behaviors, 20, 135-137.

Chen, R., \& Simons-Morton, B. (2009). Concurrent changes in conduct problems and depressive symptoms in early adolescence: A developmental person-centered approach. Developmental Psychopathology, 21, 285-307.

Choi-Kain, L. W., \& Gunderson, J. G. (2008). Mentalization: Ontogeny, assessment, and application in the treatment of borderline personality disorder. The American Journal of Psychiatry, 165, 1127-1135.

Coll, K. M., Thobro, P., \& Haas, R. (2004). Relational and purpose development in youth offenders. Journal of Humanistic Counseling, Education, and Development, 43, 41-49.

Coll, K. M., Juhnke, G. A., Thobro, P., Haas, R., \& Robinson, M. S. (2008). Family disengagement of youth offenders: Implications for counselors. The Family Journal: Counseling and Therapy For Couples and Families, 16, 359-363.

Colman, I., Murray, J., Abbott, R. A., Maughan, B., Kuh, D., Croudace, T. J., \& Jones, P. B. (2009). Outcomes of conduct problems in adolescence: 40 year follow-up of national cohort. British Medical Journal, 338, 208-216.

Crowell, S. E., Beauchaine, T. P., McCauley, E., Smith, C. J., Vasilev, C. A., \& Stevens, A. L. (2008). Parent-child interactions, peripheral serotonin, and self-inflicted injury in adolescents. Journal of Consulting and Clinical Psychology, 76, 15-21.

Daniels, J. A. (1990). Adolescent separation-individuation and family transitions. Adolescence, 97, 105-117.

Dekovic, M. (1999). Parent-adolescent conflict: Possible determinants and consequences. International Journal of Behavioral Development, 23, 977-1000.

Erickson, E. (1963). Childhood and society ( $2^{\text {nd }}$ ed.). New York: Norton.

Fonagy, P. (2001). Attachment theory and psychoanalysis. New York: The Other Press. Fonagy P., \& Target, M. (2005). Bridging the transmission gap: An end to an important mystery of attachment research? Attachment and Human Development, 7, 333- 
343.

Fonagy, P., \& Target, M. (2006). The mentalization focused approach to self pathology. Journal of Personality Disorders, 20, 544-576.

Fraley, R. C. (2002). Attachment stability from infancy to adulthood: Meta-analysis and dynamic modeling of developmental mechanisms. Personality and Social Psychology Review, 6, 123-151.

Fromme, K. (2006). Parenting and other influences on the alcohol use and emotional adjustment of children, adolescents, and emerging adults. Psychology of Addictive Behaviors, 20, 138-139.

Green, J., Kroll, L., Imrie, D., Frances, F. M., Begum, K., Harrison, L., et al. (2001). Health gain and outcome predictors during inpatient and related day treatment in child and adolescent psychiatry. Journal of the American Academy of Child and Adolescent Psychiatry, 40, 325-332.

Gunderson, J. G., \& Lyons-Ruth, K. (2008). BPD’s interpersonal hypersensitivity phenotype: A gene-environment-developmental model. Journal of Personality Disorders, 22, 22-41.

Hardy, L. T. (2007). Attachment theory and reactive attachment disorder: Theoretical perspectives and treatment implications. Journal of Child and Adolescent Psychiatric Nursing, 20, 27-40.

Hawley, G. (1988). Measure of psychosocial development manual. Odessa, FL: Psychological Assessment Resources.

Herr, N. R., Hammen, C., \& Brennan, P. A. (2008). Maternal borderline personality disorder symptoms and adolescent psychosocial functioning. Journal of Personality Disorders, 22, 451-465.

Hill, J., Fonagy, P., Safier, E., \& Sargent, J. (2003). The ecology of attachment in the family. Family Process, 42, 205-221.

Hofer, M. A. (2006). Psychobiological roots of early attachment. Current Directions in Psychological Science, 15, 84-88.

Jensen, P. S. (2008). The role of psychosocial therapies in managing aggression in children and adolescents. Journal of Clinical Psychiatry, 69, 37-42.

Keeley, M. L., \& Storch, E. A. (2009). Anxiety disorders in youth. Journal of Pediatric Nursing, 24, 26-40.

Kerns, K. A., Tomich, P. L., Aspelmeier, J. E., \& Contreras, J. M. (2000). Attachmentbased assessments of parent-child relationships in middle childhood.

Developmental Psychology, 36, 614-626.

Laible, D. J., Gustavo, C., \& Raffaelli, M. (2000). The differential relations of parent and peer attachment to adolescent adjustment. Journal of Youth and Adolescence, 29, 45-59.

Lee, J. M., \& Bell, N. J. (2003). Individual differences in attachment-autonomy configuration: Linkages with substance use and youth competencies. Journal of Adolescence, 26, 347-361.

Lyons-Ruth, K. (1999). The two-person unconscious: Intersubjective dialogue, enactive relational representation, and the emergence of new forms of relational organization. Psychoanalytic Inquiry, 19, 576-617.

Main, M., \& Goldwyn, R. (1994). Adult attachment scoring and classification system. Unpublished manuscript, University of California at Berkeley. 
Maynard, P. E., \& Olson, D. H. (1987). Circumplex model of family systems: A treatment tool in family counseling. Journal of Counseling and Development, 65, 502-504.

McWhirter, J., McWhirter, B., McWhirter, E., \& McWhirter, R. (2004). At-risk youth: A comprehensive response ( ${ }^{\text {rd }}$ ed.). Pacific Grove, CA: Brooks/Cole.

Miklowitz, D. J., \& Chang, K. D. (2008). Prevention of bipolar disorder in at-risk children: Theoretical assumptions and empirical foundations. Developmental Psychopathology, 20, 881-897.

Mikulincer, M. (1998). Attachment working models and the sense the trust: An exploration of interaction goals and affect regulation. Journal of Personality and Social Psychology, 74, 1209-1224.

Miller, M. L. (2008). The emotionally engaged analyst I: Theories of affect and their influence on therapeutic action. Psychoanalytic Psychology, 25, 3-25.

Murray, L., Halligan, S. L., Adams, G., Patterson, P., \& Goodyer, I. M. (2006). Socioemotional development in adolescents at risk for depression: The role of maternal depression and attachment style. Developmental Psychopathology, 18, 489-516.

Olson, D. H., McCubbin, H. I., Barnes, H., Larson, A., Muxen, M., \& Wilson, M. (1985). Family inventories manual. St Paul: University of Minnesota.

Ornduff, S. R. (2000). Childhood maltreatment and malevolence: Quantitative research findings. Clinical Psychology Review, 20, 997-1018.

Rempel, J. K., Holmes, J. G., \& Zanna, M. P. (1985). Trust in close relationships. Journal of Personality and Social Psychology, 49, 95-112.

Richmond, M. K., \& Stocker, C. M. (2006). Associations between family cohesion and adolescent siblings’ externalizing behavior. Journal of Family Psychology, 20, 663-669.

Riggs, S. A., Sahl, G., Greenwald, E., Atkison, H., Paulson, A., \& Ross, C. A. (2007). Family environment and adult attachment as predictors of psychopathology and personality dysfunction among inpatient abuse survivors. Violence and Victims, 22, 577-598.

Sameroff, A. J., \& MacKenzie, M. J. (2003). Research strategies for capturing transactional models of development: The limits of the possible. Development and Psychopathology, 15, 613-646.

Scindler, A., Thomasius, R., Sack, P. M., Gemeinhardt, B., Kustner, U., \& Eckert, J. (2005). Attachment and substance use disorders: A review of the literature and a study in drug dependent adolescents. Attachment and Human Development, 7, 207-228.

Siegal, D. J. (1999). The developing mind: How relationships and the brain interact to shape who we are. New York: Guilford Press

Steinberg, S. J., \& Davila, J. (2008). Romantic functioning and depressive symptoms among early adolescent girls: The moderating role of parental emotional availability. Journal of Clinical Child and Adolescent Psychology, 37, 350-62.

Sullivan, H. S. (1953). The interpersonal theory of psychiatry. New York: Norton. Sunday, S., Labruna, V., Kaplan, S., Pelcovitz, D., Newman, J., \& Salzinger, S. (2008). Physical abuse during adolescence: Gender differences in the adolescents’ 
perception of family functioning and parenting. Child Abuse and Neglect, 32, 518.

Taliaferro, L. A., Rienzo, B. A., Miller, M. D., Pigg, R. M., Jr., \& Dodd, V. J. (2008). High school youth and suicide risk: Exploring protection afforded through physical activity and sport participation. Journal of School Health, 78, 545-553.

Tonge, B. J., Hughes, G. C., Pullen, J. M., Beaufoy, J., \& Gold. S. (2008). Comprehensive description of adolescents admitted to a public psychiatric inpatient unit and their families. Australian and New Zealand Journal of Psychiatry, 42, 627-635.

Trumpeter, N. N., Watson, P. J., O’Leary, B. J., \& Weathington, B. L. (2008). Selffunctioning and perceived parenting: Relations of parental empathy and love inconsistency with narcissism, depression, and self-esteem. The Journal of Genetic Psychology, 169, 51-71.

Tucker, J. S., Ellickson, P. L., \& Klein, D. J. (2008). Growing up in a permissive household: What deters at-risk adolescents from heavy drinking? Journal of the Study of Alcohol and Drugs, 69, 528-534.

Van der Vorst, H., Engels, R. C., Meeus, W., Dekovic, M., \& Vermulst, A. (2006). Parental attachment, parental control, and early development of alcohol use: A longitudinal study. Psychology of Addictive Behaviors, 20, 107-116.

Wallin, D. J. (2007). Attachment in psychotherapy. New York: Guildford Press.

Young, J. E., Klosko, J. S., \& Weishaar, M. E. (2003). Schema therapy: A practitioner's guide. New York: Guilford Press.

Zegers, M. A., Schuengel, C., Van IJzendoorn, M. H., \& Janssens, J. M. (2008). Attachment and problem behavior of adolescents during residential treatment. Attachment and Human Development, 10, 91-103. 
Table 1

Correlations among Adaptability, Cohesion, Trust, and Intimacy

\begin{tabular}{|c|c|c|c|c|}
\hline & Adaptability & Cohesion & Trust & Intimacy \\
\hline Adaptability & & $.45 * *$ & $.12 *$ & $.17^{* *}$ \\
\hline Cohesion & & & $.13^{*}$ & .07 \\
\hline Trust & & & & \\
\hline Intimacy & & & & \\
\hline
\end{tabular}

Summary of Regression Analysis for Variables Predicting Trust

\begin{tabular}{|lcccc|}
\hline Variable & $\mathrm{B}$ & $\mathrm{SE}$ & $\beta$ & $\mathrm{t}$ \\
\hline Cohesion & .122 & .047 & .142 & $2.6^{*}$ \\
Adaptability & -.068 & & & -1.08 \\
& & & & \\
\hline
\end{tabular}

$$
\mathrm{P}<.01^{*}
$$

Summary of Regression Analysis for Variables Predicting Intimacy

\begin{tabular}{|lcccc|}
\hline Variable & B & SE & $\beta$ & $t$ \\
\hline Trust & .576 & .039 & .633 & $14.7^{*}$ \\
Adaptability & .074 & & & 1.72 \\
Cohesion & -.011 & & & -0.26 \\
\hline
\end{tabular}

$\mathrm{P}<.01^{*}$ 